\title{
La estrategia populista: ¿un riesgo para la democracia o una herramienta oportuna para el cambio político?
}

\section{The Populist Strategy: a Risk for Democracy or an Opportune Device for Political Change?}

\author{
José Manuel Rivas Otero ${ }^{1}$ \\ Universidad Sergio Arboleda (Colombia)
}

Recibido: 31-01-19

Aprobado: 28-05-19

\section{Resumen}

El objetivo de este artículo es evaluar si la estrategia populista conlleva oportunidades o peligros para la democracia y para ello se analizan los principales elementos del discurso populista a la luz de las intervenciones de dos líderes europeos, Pablo Iglesias y Marine Le Pen. Se sostiene que la estrategia populista no implica por sí misma un riesgo para la democracia sino que depende del tipo de demandas sociales que se articulen y de los valores (contra)hegemónicos que se quieran transmitir a la opinión pública. La estructura del artículo es la siguiente: en primer lugar, se realiza una revisión crítica de la literatura sobre populismo; en segundo lugar, se analizan tanto la estructura formal como el carácter vacuo y disputado del discurso populista a partir de las intervenciones de Iglesias y Le Pen; por último, se presentan unas reflexiones finales. Francia.

Palabras-clave: populismo, democracia, análisis de discurso, España,

\footnotetext{
${ }^{1}$ (jose.rivas@usa.edu.co). Profesor de la Universidad Sergio Arboleda y la Universidad Jorge Tadeo Lozano, en Bogotá. Doctor en Estado de Derecho y Gobernanza Global (Ciencia Política) por la Universidad de Salamanca y máster en Estudios Latinoamericanos por la misma universidad. Ha sido investigador predoctoral de la Universidad de Salamanca y profesor en la Universidad Nacional de Colombia y la Pontificia Universidad Javeriana, en Bogotá. También ha sido visiting scholar en la Universidad de Boston. Sus líneas de investigación son el liderazgo político, la representación, las élites políticas y la resolución de conflictos.
} 


\begin{abstract}
The aim of this paper is to evaluate whether the populist strategy involves opportunities or risks for democracy. To do so I analyze the main elements of the populist discourse, following the interventions of two European national political leaders, Pablo Iglesias and Marine Le Pen. Results show that the populist strategy does not entail by itself a risk for democracy, but will depend on the type of social demands that are articulated, and the (counter)hegemonic values that political leaders want to transmit to the public opinion. The structure of the article is as follows: first, the paper critically reviews the literature about populism; second, the formal structure and the vacuous and disputed nature of the populist discourse, from the interventions of Iglesias and Le Pen, are analyzed; the last section presents the final reflections.
\end{abstract}

Key-words: populism, democracy, discourse analysis, Spain, France.

Hoy en día uno de los adjetivos más recurrentes para descalificar al adversario político es el de populista. En Europa se ha utilizado para designar a movimientos políticos ideológicamente opuestos como los liderados por Pablo Iglesias en España ${ }^{2}$ o Marine Le Pen en Francia. El populismo se empleó, en su origen, para caracterizar a movimientos políticos que perseguían la defensa de los intereses del pueblo frente a la oligarquía, pero actualmente predomina una visión peyorativa de este fenómeno influida por el rechazo a la política de masas, propio del pensamiento liberal. Como recuerda De la Torre:

Otra característica de las defensas a la democracia liberal, también herencia del siglo XIX, es que se basan en un menosprecio a los de abajo. El miedo, la aversión y el asco de las élites hacia sus compatriotas más pobres y menos blancos han ido de la mano con la idea de que la democracia liberal es una empresa civilizadora que educará y modernizará a los de abajo, siempre vistos como no preparados aún para ejercer sus derechos democráticos. Esta ambigüedad entre defender la democracia liberal y temer al "populacho" es una constante en la forma en que las élites políticas han entendido la democracia (De la Torre 2015: 127).

\footnotetext{
${ }^{2}$ En una entrevista, el líder de Podemos reivindicó la estrategia populista al declarar: "Hay un nivel de satisfacción enorme con las nociones que hemos puesto encima de la mesa y lo he visto con la recepción de mis últimos artículos al explicar qué es la centralidad del tablero, por qué entendemos que la geografía izquierda-derecha no funciona; al explicar que ese estilo plebeyo que algunos han definido como populismo de izquierdas es clave para construir los elementos agregadores para que se produzca un cambio político" (García-Abadillo 17 de mayo de 2015).
} 
El rechazo al populismo no es algo reciente. En la antigüedad clásica, las élites políticas, sociales y económicas, pero también los intelectuales, advirtieron del riesgo de las formas políticas que otorgaban el poder a las masas ya que no perseguían el interés general, debilitaban las instituciones republicanas y podían derivar en regímenes tiránicos (Aristóteles 2000). Como entonces, muchos estudiosos actuales del populismo siguen reemplazando el análisis por la condena moral. Sin embargo, como afirma Laclau (2007: 230), el problema no es condenar el populismo sino no proponer una explicación que remplace a la condenación.

Para superar esto último, aquí se entiende al populismo como una estrategia discursiva, una forma de hacer política a través del discurso que puede ser útil para construir hegemonía ${ }^{3}$ y propiciar el cambio político (Laclau 2007). El objetivo de este artículo es evaluar si esta estrategia conlleva oportunidades o peligros para la democracia ${ }^{4}$ y para ello se analizan los principales elementos del discurso populista a la luz de las intervenciones de dos líderes europeos, Iglesias y Le Pen. Se sostiene que la estrategia populista no implica por sí misma un riesgo para la democracia sino que depende del tipo de demandas sociales que se articulen y de los valores hegemónicos que se quieran transmitir a la opinión pública.

La estructura del artículo es la siguiente: en primer lugar, se realiza una revisión crítica de la literatura sobre populismo; en segundo lugar, se analizan tanto la estructura formal como el carácter vacuo y disputado del discurso populista a partir de las intervenciones de Iglesias y Le Pen; finalmente, se presentan unas reflexiones finales.

\section{Una revisión crítica de las aproximaciones teórico-normativas del populismo}

\section{Un concepto en disputa}

El concepto populismo presenta problemas de ambigüedad, vaguedad y estiramiento conceptual (Freidenberg 2007: 20) y se encuentra "a mitad de camino entre lo descriptivo y lo normativo" (Laclau 2007: 15). Se utilizó por primera vez para denominar a los movimientos políticos agrícolas surgidos en

\footnotetext{
${ }^{3}$ La hegemonía, en términos de Gramsci (1981), consiste en la imposición o superior consideración de los valores de un grupo social con relación al resto en una etapa histórica determinada. Para lograr establecerla se requiere "articular a distintos grupos y crear una voluntad colectiva entre ellos" (Errejón y Mouffe 2015: 34). Sobre la aplicación de la teoría de la hegemonía en la acción colectiva, véase Quiroga (2013).

${ }^{4}$ En este artículo, la democracia es entendida no solo como respeto a los derechos individuales y a la separación de poderes sino también como regla de la mayoría y defensa de la soberanía popular (Mouffe 2011).
} 
la segunda mitad del siglo XIX: el de los Narodniki en Rusia ${ }^{5}$ y el agrupado en torno al Partido Populista de los Estados Unidos ${ }^{6}$ (Walicki 1971; Canovan 1981). Estos populismos originarios constituyeron una reacción de los sectores campesinos frente al desafío de la modernización industrial capitalista (Worsley 1966). Ya en el siglo XX, durante el periodo de entreguerras, el término se empleó para referirse a movimientos políticos muy heterogéneos, tanto rurales como urbanos, en América Latina, Asia, los Balcanes y Europa Central y Oriental (Ionescu 1969; Lenin 1978; Germani 1978).

Después de la Segunda Guerra Mundial, la literatura académica comenzó a interesarse por este fenómeno y surgieron diversas teorías que se pueden clasificar en cuatro grupos: formalistas, estructurales, evasivas y posmarxista; todas ellas con un denominador común: la referencia al pueblo (Moscoso 1989).

Los teóricos formalistas describieron el populismo como un fenómeno de masas con una serie de rasgos entre los que destacan la presencia de un líder carismático, el desdén hacia las ideologías y las estructuras partidarias, y el uso de un discurso emocional que apela a la tradición popular y divide a la sociedad en dos grupos antagónicos: pueblo y antipueblo ${ }^{7}$ (Lambert 1964; Moscoso 1989). Estas teorías se inspiraron autores previos como Le Bon (1968) y Ortega y Gasset (2009), quienes, sin referirse expresamente al populismo, describieron la política de masas como una anomalía fruto de la sugestión que ejerce el líder sobre las masas, advirtiendo del peligro que corre el individuo cuando se diluye en un grupo ${ }^{8}$. En palabras de Ortega y Gasset:

\begin{abstract}
Hay un hecho que, para bien o para mal, es el más importante en la vida pública europea de la hora presente. Este hecho es el advenimiento de las masas al pleno poderío social. Como las masas, por definición, no deben ni pueden dirigir su propia existencia, y menos regentar la sociedad, quiere decirse que Europa sufre ahora la más grave crisis que a pueblos, naciones, culturas, cabe padecer. Esta crisis ha sobrevenido más de una vez en la historia. Su fisonomía y sus consecuencias son conocidas. También se conoce su nombre. Se llama la rebelión de las masas (Ortega y Gasset 2009: 45-46).
\end{abstract}

${ }^{5}$ Los populistas rusos fueron calificados por Lenin como demócratas pequeñoburgueses que luchaban contra la autocracia y por la abolición de la propiedad agraria terrateniente en Rusia, pero que no tenían nada de socialistas porque no buscaban acabar con la explotación sino solamente atenuarla (Lenin 1978, 1979).

${ }^{6}$ Según Lasch (1996: 77), para los populistas estadounidenses "la confianza en uno mismo es la esencia de la democracia".

7 El antipueblo adopta diferentes denominaciones según el emisor y la coyuntura histórica: élite, bloque de poder, oligarquía, casta, privilegiados, "los de arriba", etc. Para Errejón, en la indefinición de este tipo de términos radica el poder movilizador del populismo (Errejón y Mouffe 2015: 121).

${ }^{8}$ Esta concepción negativa de la política de masas también influyó en la obra de Hannah Arendt (1987), para quien la alianza de parte de la élite con "el populacho", con su forma de entender la política, es la antesala del totalitarismo, entendiendo a este último como la forma de gobierno basada en la movilización de las masas a través de la propaganda.

Araucaria. Revista Iberoamericana de Filosofía, Política, Humanidades y Relaciones Internacionales, año $21, \mathrm{n}^{\circ} 42$. Segundo semestre de 2019. Pp. 605-628. ISSN 1575-6823 e-ISSN 2340-2199 doi: 10.12795/araucaria.2019.i42.26 
Algunas propuestas teóricas posteriores bebieron de las teorías formalistas. Mair (2002), por ejemplo, definió al populismo como un estilo político caracterizado por la relación entre líder y seguidor, sostenido por un vínculo estructurado en torno a las apelaciones al pueblo. Freidenberg (2007: 25), por su parte, lo entendió "como un estilo de liderazgo" que se caracteriza por el uso de un discurso polarizador y el desdén hacia las estructuras de mediación.

Según Laclau (1978: 168), gracias a estas teorías el populismo dejó de considerarse como "un rasgo común a varios movimientos y se transformó en un concepto sintético que define o simboliza al conjunto de rasgos característicos del movimiento concreto que se estudia". Pese a ello, los argumentos de los teóricos formalistas estaban fuertemente sesgados y escondían un profundo desprecio por la participación política de las masas.

Las teorías estructurales abordaron el populismo atendiendo a las estructuras económicas y sociales. Bajo esta etiqueta se agruparon tres perspectivas teóricas distintas: funcionalista, de la dependencia y de la alianza multiclasista. La primera se concentró en los movimientos populistas ${ }^{9}$ latinoamericanos, concibiéndolos como productos de la transición de la sociedad tradicional a la sociedad moderna. Sus dos referentes teóricos fueron Germani y Di Tella. El primero destacó tres rasgos de los movimientos populistas: abogaban por la incorporación y participación política de las masas, recurrían al nacionalismo y poseían un semblante autoritario (Germani 1962); mientras que el segundo enfatizó en otros dos: se agrupaban en torno a un líder fuerte y sostenía una ideología anti statu quo (Di Tella 1965).

La teoría de la dependencia de Cardoso y Faletto (1969), al igual que la funcionalista, centró su atención en los movimientos nacional-desarrollistas latinoamericanos a los que caracterizó como fenómenos históricos frutos del tránsito de economías agroexportadoras dependientes hacia economías con mayor desarrollo industrial.

Por último, la teoría de la alianza multiclasista describió el populismo atendiendo a la estructura de clases. Según esta corriente, en los países latinoamericanos la crisis agroexportadora provocó contradicciones en el seno de la clase dominante y dio lugar a una alianza multiclasista integrada por organizaciones y movimientos políticos populares y sectores burgueses (Ionescu y Gellner 1969; Ianni 1973; Germani 1978); el populismo no fue un nuevo tipo de Estado sino "una forma de hacer Estado" (Moscoso 1989: 186) que permitió la inclusión de las masas en la política, pero situándolas en una posición subordinada.

Aunque la tradición estructural explicó con rigor el surgimiento del populismo, circunscribió este fenómeno a un momento histórico concreto, incurriendo en el economicismo y adoptando una perspectiva eurocéntrica al

\footnotetext{
${ }^{9}$ También llamados nacional-populares.
}

Araucaria. Revista Iberoamericana de Filosofia, Politica, Humanidades y Relaciones Internacionales, año $21, \mathrm{n}^{\circ} 42$. Segundo semestre de 2019. Pp. 605-628. ISSN 1575-6823 e-ISSN 2340-2199 doi: 10.12795/araucaria.2019.i42.26 
asociar a los movimientos nacional-populares con desarrollo económico tardío de los países latinoamericanos. Además, se centró en las estructuras sociales y económicas, desestimando el papel de los actores políticos.

Las teorías evasivas renunciaron a definir el populismo y trataron de abordarlo de manera intuitiva. Su principal exponente fue Canovan (1981) quien, con el fin de superar la ambigüedad del concepto, optó por elaborar tipologías a partir de los casos reales que la literatura consideraba populistas. De este modo, las corrientes evasivas no fueron teorías como tales, sino que se limitaron a describir y/o explicar movimientos políticos catalogados previamente como populistas (Mouzelis 1985).

Finalmente, el posmarxismo entendió el populismo como una lógica política que buscaba confrontar los valores hegemónicos mediante una construcción discursiva ${ }^{10}$ capaz de dividir a la sociedad en dos campos antagónicos: el pueblo y la élite (Mude y Rovira 2013: 5). Para elaborar una teoría del populismo, autores posmarxistas como Laclau y Mouffe criticaron el postulado marxista del reduccionismo de clase ${ }^{11}$ y concibieron lo político con base en la lógica amigo-enemigo, rescatada de Carl Schmitt (Laclau y Mouffe 1987; Mouffe 2011).

En la teoría posmarxista los antagonismos no son inherentes a la contradicción entre medios productivos y relaciones de producción sino que tienen lugar en el plano de las identidades (Laclau 1993). A partir de la idea de que la función central de la ideología es interpelar a los individuos como sujetos (Althusser 2004), Laclau y Mouffe (1987) sostuvieron que los líderes políticos son capaces de articular discursos exhortativos como primer paso en la construcción de su hegemonía ${ }^{12}$. Uno de estos discursos es el populista que construye una identidad colectiva y establece una cadena de equivalencias entre múltiples demandas sociales, es decir, hace que demandas que por sí solas son diferenciales o excluyentes pasen a ser equivalentes o aglutinadoras. Este tipo de discurso toma elementos ideológicos de las tradiciones popular y democrática ${ }^{13}$ para instar al pueblo a luchar contra el sistema dominante (Laclau 1978).

\footnotetext{
${ }^{10}$ Sobre el constructivismo y su relación con el liberalismo véase Ocho y Prado (2017).

11 Según este postulado todo elemento ideológico está adscrito a una clase social, es decir, el socialismo sería la ideología de la clase obrera, el liberalismo, la de la burguesía, el fascismo, la de la pequeña burguesía, y así sucesivamente. Igualmente, elementos ideológicos compartidos por distintas ideologías, como el nacionalismo, también tendrían adscripción de clase. Sin embargo, para Laclau (2007: 188-89), "no hay motivo para que las luchas que tienen lugar dentro de las relaciones de producción deban ser los puntos privilegiados de una lucha global anticapitalista". Véase Rivas (2018).

12 Para el posmarxismo, gran parte de la batalla por la hegemonía entre las distintas facciones políticas de la sociedad se libra en este terreno discursivo (Laclau 1978, 2007; Laclau y Mouffe 1987).

${ }_{13}$ Mientras las luchas democráticas "suponen una pluralidad de espacios políticos", las populares se dan "cuando se construye discursivamente la división de un único espacio político en dos campos opuestos": el pueblo y la élite (Laclau y Mouffe 1987: 158).
} 
Con el posmarxismo, el populismo pasó a considerarse un fenómeno ideológico, una forma de hacer política a través de "la presentación [discursiva] de las interpelaciones popular-democráticas como conjunto sintéticoantagónico respecto a la ideología dominante" (Laclau 1978: 191). Aunque se le ha reprochado su excesiva abstracción, esta teoría enfatizó en el discurso como constructor de identidades colectivas en lugar de centrarse en coyunturas históricas o movimientos políticos particulares como hacen el resto de teorías. Por eso, aquí se entiende el populismo desde esta óptica, como una estrategia discursiva que puede implementarse para obtener el poder político (Laclau 1987) y/o legitimar desde el gobierno la posterior acción política (Freidenberg 2007; De la Torre 2015).

\section{El populismo y su relación con la democracia}

El populismo ha mantenido una relación peculiar con la democracia. Los líderes políticos que utilizan esta estrategia reclaman el poder para el pueblo y se llaman a sí mismos verdaderos demócratas (Canovan 2004: 244), mientras que sus detractores los acusan de demagogos o autoritarios. En la literatura académica coexisten estas dos visiones del populismo: la liberal, que considera al populismo como una amenaza, y la posmarxista, que lo percibe como una oportunidad para el cambio político que contribuye a ampliar los espacios democráticos o incluso como una condición indispensable para que haya democracia (Laclau 2007).

Entre los defensores de la primera visión se encuentran Canetti y De la Torre. Según el primero los agentes sociales se sienten tentados a formar parte de la masa, por lo que más que evitar o censurar esta pulsión, resulta necesario tratar de movilizarla de tal modo que no suponga un peligro para las instituciones democráticas (Canetti 2013). Para De la Torre (2000) el populismo se dibuja sobre la distinción maniquea entre el pueblo puro y la élite corrupta, y esto deja poco espacio para el pluralismo; además, esta estrategia discursiva mantiene una relación problemática con las instituciones liberales ya que entiende la democracia como "la ocupación de espacios públicos a favor de un líder que encarna los sueños y esperanzas democratizadoras", y contiene elementos autoritarios tales como un fuerte liderazgo, la concepción homogénea de pueblo o el maniqueísmo (De la Torre 2015: 11-12).

Esta relación entre populismo y autoritarismo ha sido señalada también por otros autores que subrayan que el carácter demagógico de este tipo de discursos tiene consecuencias negativas para la democracia y conduce a escenarios autoritarios (Romero 1996; Krauze 14 de octubre de 2005; Lassalle 2017). De hecho, Aristóteles (2000) ya identificaba a la demagogia con la tiranía política arropada por el pueblo, y el Diccionario de la Real Academia 
Española define este concepto como la "práctica política consistente en ganarse con halagos el favor popular" y, en su segunda acepción, como una "degeneración de la democracia" (DRAE 2014). En este sentido, desde una perspectiva historiográfica, Álvarez-Junco $(1987,1990)$ vincula el uso de la demagogia populista con la actitud caudillista y autoritaria de algunos líderes políticos.

No obstante, algunos académicos liberales reconocen que el populismo posee algunos efectos democratizadores. Para Freidenberg (2007: 9), aunque este tipo de discurso puede generar debilidad institucional, autoritarismo y polarización, también "favorece el acceso de la gente común a las instituciones". Según Mude y Rovira (2013: 18) el populismo puede ser un correctivo y a la vez una amenaza para la democracia: por un lado, es esencialmente democrático ya que no se opone a la representación e incluso la acepta cuando la ejerce alguien del pueblo; pero por otro, es ambivalente hacia los postulados de la democracia liberal, resulta hostil hacia el pluralismo y las minorías, y prioriza el poder político frente a otros centros de poder institucionales.

Frente a los teóricos liberales, los posmarxistas defienden la existencia de un vínculo positivo entre el populismo y la democracia, redefiniendo el proyecto socialista "en términos de una radicalización de la democracia, es decir, como articulación de las luchas contra las diferentes formas de subordinación" (Laclau y Mouffe 1987: ix). La democracia se define así como "un conjunto de símbolos, valores, etc. -en suma, interpelaciones- por las que el pueblo cobra conciencia de su identidad a través de su enfrentamiento con el bloque de poder" (Laclau 1978: 121). Estos autores recuerdan que existen dos tradiciones democráticas, la popular y la liberal; la primera entiende la democracia como soberanía popular y regla de la mayoría, y la segunda, como respeto a los derechos individuales y equilibrio de poderes ${ }^{14}$. Mouffe (2011) sostiene que el populismo sirve para articular ambas tradiciones, mientras que Laclau (2007) lo considera indispensable para la existencia misma de la democracia ${ }^{15}$.

Panizza resume las limitaciones tanto de la visión liberal como de la posmarxista:

Quienes sostienen que, por dar voz a los excluidos y reivindicar la soberanía popular, el populismo es fundamentalmente democrático, deberían considerar todos los casos en que los movimientos y regímenes populistas no lo han sido. Por otra parte, quienes sostienen que se trata de una degeneración de la democracia, deberían considerar el genuino soporte popular del que gozan los

\footnotetext{
${ }^{14}$ Aunque hoy predomina el concepto liberal de democracia, desde la época clásica hasta finales del siglo XVIII el pensamiento occidental entendió la democracia en el sentido popular, como el gobierno de los pobres, como una forma de gobierno que suponía "una amenaza de clase" (Macpherson 1997: 20).

${ }^{15}$ En palabras de Laclau (2007: 213), "sin la producción de vacuidad (discurso populista) no hay pueblo, no hay populismo, pero tampoco hay democracia".
}

Araucaria. Revista Iberoamericana de Filosofia, Política, Humanidades y Relaciones Internacionales, año $21, \mathrm{n}^{\circ} 42$ Segundo semestre de 2019. Pp. 605-628. ISSN 1575-6823 e-ISSN 2340-2199 doi: 10.12795/araucaria.2019.i42.26 
líderes populistas y dejar de apelar a argumentos antidemocráticos sobre la ignorancia del pueblo o la sinrazón de las masas (Panizza 2008: 83).

Este autor refuta los argumentos liberales por ignorar el soporte democrático del populismo y desdeñar políticamente a las masas, pero no hace lo propio con los argumentos posmarxistas. Si bien es cierto que no todos los movimientos y regímenes populistas son democráticos (como se argumenta en este artículo), estos ejemplos negativos no invalidan que el populismo sí pueda ser democrático, al igual que el hecho de que existan regímenes liberales no democráticos no necesariamente implica que el liberalismo sea antidemocrático. Como recuerda Mouffe, las élites tradicionales utilizan a las instituciones

como trincheras frente a las masas, como si toda institución, por el hecho de serlo, aunque no responda a las necesidades de sus gentes o sea poco democrática, sea siempre preferible a la irrupción constituyente del pueblo (...), como si un régimen no pudiese ser a la vez popular y republicano (Errejón y Mouffe 2015: 81).

Es más, a veces son las propias instituciones representativas o legales las que ponen límites a la democracia, y las masas, impulsadas por líderes transformadores, las que pelean por derribarlos, como ocurrió con las luchas por el sufragio universal, el sufragio femenino o los derechos civiles.

Más sólida que la de Panizza es la reflexión de Duverger sobre las dos formas que existen de entender la política:

Desde que los hombres reflexionan sobre la política, han oscilado entre dos interpretaciones diametralmente opuestas. Para unos, la política es esencialmente una lucha, una contienda que permite asegurar a los individuos y a los grupos que detentan el poder su dominación sobre la sociedad, al mismo tiempo que la adquisición de las ventajas que se desprenden de ello. Para otros, la política es un esfuerzo por hacer reinar el orden y la justicia, siendo la misión del poder asegurar el interés general y el bien común (...). Para los primeros, la política sirve para mantener los privilegios de una minoría sobre la mayoría. Para los segundos, es un medio de realizar la integración de todos los individuos en la comunidad y de crear la "ciudad perfecta" de la que hablaba Aristóteles (Duverger 1982: 15).

El teórico francés distingue aquí las dos visiones expuestas anteriormente sin mencionar los conceptos de populismo y democracia. La primera interpretación de la política es la que hacen los posmarxistas: una lucha, una contienda, por la dominación política, social y cultural (hegemonía). La segunda es la que hacen los liberales: una forma de lograr el orden, el bien común y la integración. Más adelante, Duverger (1982: 15) aclara que el tomar una u otra visión depende de la situación socioeconómica y de la pertenencia de clase: se 
fomenta la politización y el cambio político (recalcando la necesidad de que las demandas que se articulen sean democráticas), o se asegura la vigencia del statu quo. De acuerdo con este planteamiento, las reacciones liberales contra el populismo, más que preocupaciones legítimas por la estabilidad o la calidad de la democracia, serían expresiones de aquellos que, desde la élite (también académica), temen el empoderamiento de las masas ${ }^{16}$.

\section{El discurso populista: los ejemplos de Pablo Iglesias y Marine Le Pen}

\section{Estructura formal: apelación al pueblo y creación de identidad}

El discurso constituye la piedra angular de la estrategia populista de acceso y ejercicio del poder político ya que ejerce como "una de las formas de construir unidad de grupo" (Laclau 2007: 97). Para articular el discurso populista se requieren condiciones que son ajenas a su estructura formal y contenido material: una coyuntura de crisis institucional, de representación o de régimen ${ }^{17}$; un movimiento político que busque cambiar el orden establecido; y la presencia de un líder carismático ${ }^{18}$ que mantenga una relación directa con sus seguidores (Freidenberg 2007). Esta última condición es fundamental, ya que el líder actúa como emisor y su liderazgo equivale a "la unificación simbólica en torno a una individualidad [que] es inherente a la formación de un pueblo" (Laclau 2007: 129). Como planteaba Le Bon:

Una de las funciones más importantes de un estadista consiste entonces en bautizar con palabras populares, o al menos indiferentes, cosas que la multitud no puede soportar bajo sus antiguas denominaciones. El poder de las palabras es tan fuerte que bastará con designar con términos bien elegidos las cosas más odiosas para volverlas aceptables a las masas (cit. en Laclau 2007: 39-40).

En este artículo se analizan los elementos fundamentales del discurso populista a la luz de las intervenciones de dos políticos europeos: Pablo Iglesias, líder de Podemos, y Marine Le Pen, lideresa del Frente Nacional de Francia. Sus formaciones políticas son casos exitosos de estrategia populista desde la

\footnotetext{
${ }^{16}$ La percepción negativa de Le Bon hacia las masas y el pueblo no solo ha sido asumida por el liberalismo, sino también por algunos teóricos de izquierda que trasladan la culpa de sus derrotas políticas y electorales a la ignorancia del pueblo, sosteniendo un discurso elitista esencialmente antidemocrático. Un ejemplo claro fue la tribuna firmada por John Carlin en El País, en la que acusaba a los votantes del entonces candidato republicano Donald Trump de no poseer "el área de materia gris encargada del razonamiento" (Carlin 15 de febrero de 2016).

${ }_{17}$ Como sostiene Laclau (1978: 231), "cada vez que el sistema capitalista experimentó en Europa occidental una crisis grave, florecieron diversas formas de populismo".

${ }^{18}$ Un líder es carismático siempre que los seguidores perciban cualidades excepcionales en él (Knight 1998; Weber 2006).
}

Araucaria. Revista Iberoamericana de Filosofía, Política, Humanidades y Relaciones Internacionales, año $21, \mathrm{n}^{\circ} 42$ Segundo semestre de 2019. Pp. 605-628. ISSN 1575-6823 e-ISSN 2340-2199 doi: 10.12795/araucaria.2019.i42.26 
oposición que han logrado importantes apoyos electorales. Del primero se toma el discurso que dio el 31 de enero de 2015 en la Puerta del Sol de Madrid con motivo de la Marcha del Cambio convocada por su partido, y de Le Pen la intervención que hizo el 10 de diciembre de 2015 en París, tres días antes de la celebración de la segunda vuelta de las elecciones regionales en Francia.

El discurso populista posee dos características: interpela al pueblo como sujeto político (Moscoso 1989); y genera identidad popular mediante la lógica de la diferencia, esto es, confrontando al pueblo con su antagonista, y la lógica de la equivalencia o semejanza, es decir, haciendo equivalentes y aglutinadoras demandas sociales que por sí mismas son diferenciales y excluyentes ${ }^{19}$ (Laclau 1978; 2007).

Con relación a la primera característica, la principal tarea del líder populista es "construir un pueblo, una voluntad general a partir de los dolores de los subalternos" (Errejón y Mouffe 2015: 32). En este sentido, el pueblo se concibe como la pleb que reclama ser el populus legítimo (Laclau 2007), entendiendo a la primera como el sujeto antagonista del bloque de poder y al segundo como el sujeto portador de la soberanía.

La apelación al pueblo puede identificarse tanto en el discurso de Iglesias como en el de Le Pen. El primero se refiere al sujeto popular cuando declara: "Es emocionante ver a un pueblo sonreír en la Puerta del Sol. Un pueblo con voz de gigante que pide cambio, justicia social y democracia" ${ }^{20}$. La lideresa francesa, por su parte, arenga a los suyos afirmando:

\begin{abstract}
Dimanche notre peuple, ce peuple que les élites méprisent profondément et ignorent souverainement, ce peuple dont les gouvernants se revendiquent pour faire perdurer leurs privilèges exorbitants, le peuple de France a ébranlé l'oligarchie, ses certitudes, son indifférence, son arrogance ${ }^{21}$.
\end{abstract}

También se puede apelar al pueblo a través de otras categorías como nación, plebe, gente, "los de abajo", etc. Por ejemplo, Iglesias utiliza habitualmente la palabra 'gente': "Veo aquí gente digna" / "Esa gente valiente y humilde" / "Esa gente valiente está aquí y ahora", aunque también otras como 'los de abajo' y 'los humildes'. Mientras que Le Pen prefiere usar los términos 'le peuple', 'la Nation' o 'la France': "Nous, nous sommes des partisans de la nation, de l'assimilation républicaine qui fait des Français

${ }^{19}$ La lógica de la diferencia consiste en afirmar la particularidad de un grupo señalando los elementos que le distinguen de otro; mientras que la lógica de la equivalencia radica en sacrificar parte de la particularidad de los miembros de un grupo, destacando lo que tienen en común y que les distinguen de otro grupo antagónico (Laclau 2007).

${ }^{20}$ Las citas están tomadas de Iglesias (31 de enero de 2015) y Le Pen (10 de diciembre de 2015). A partir de aquí se omiten estas dos referencias para no saturar el texto.

${ }^{21}$ Traducción: "El domingo nuestro pueblo, ese pueblo que las élites desprecian profundamente e ignoran supremamente, ese pueblo cuyos gobernantes pretenden perpetuar sus privilegios excesivos, el pueblo de Francia sacudió a la oligarquía, a sus convicciones, su indiferencia, la arrogancia".

Araucaria. Revista Iberoamericana de Filosofia, Política, Humanidades y Relaciones Internacionales, año $21, \mathrm{n}^{\circ} 42$. Segundo semestre de 2019. Pp. 605-628. ISSN 1575-6823 e-ISSN 2340-2199 doi: 10.12795/araucaria.2019.i42.26 
de toutes origines les membres solidaires d'une seule communauté, la communauté nationale"'22.

En cuanto a la segunda característica, una forma de gestar identidad popular es recurriendo al uso de la dicotomía pueblo-antipueblo (lógica de la diferencia) para simplificar el espacio público. Como señala Errejón (2015: 50), el antipueblo es imprescindible para la construcción del pueblo ya que es "el adversario que marca la imposibilidad de lo que es percibido como legítimo".

En los discursos de Iglesias y Le Pen se pueden observar varios ejemplos. El líder español confronta al pueblo (los de abajo, los humildes, etc.) frente a los gobernantes: "fueron los de siempre, los de abajo, los humildes, los que se enfrentaron a la vergüenza y la cobardía de unos gobernantes que solo defendían sus privilegios sin importarles nada más" / "los recortes y políticas de austeridad están dividiendo a nuestro país en dos: los que se han beneficiado y los que están peor que antes, los de arriba y los de abajo". Por su parte, la política francesa distingue al pueblo de una casta dirigente que se esconde detrás de un muro y "espérait se survivre de génération en génération durant l'éternité" 23 , haciendo una contraposición entre los mundialistas y los patriotas:

(...) entre ceux qui accompagnent voire organisent la disparition de notre nation millénaire et ceux qui travaillent à son renouveau, entre ceux qui se sont résignés à l'effacement et ceux qui se battent, debout sans faillir pour le rayonnement de notre pays ${ }^{24}$.

Otra forma de crear identidad es articulando las diferentes demandas sociales (lógica de la equivalencia) con base en interpelaciones populardemocráticas que tienen una gran aceptación por las multitudes, ya que a lo largo de la historia estas últimas han poseído un instinto nivelador que les ha llevado "a buscar cierto grado de justicia social elemental a expensas de los ricos” (Rudé 1964: 224-225).

La articulación de este tipo de demandas es muy clara en el discurso de Iglesias, por una parte, cuando saluda al auditorio en todas las lenguas del Estado español: "Bona tarda. Arratsaldeon. Boas tardes. Bienvenidos a Madrid"; por otra parte, cuando enumera las distintas demandas sociales para asumirlas dentro de la misma lucha:

${ }^{22}$ Traducción: "Nosotros, nosotros somos partidarios de la nación, de la asimilación republicana que hace que todos los franceses sean miembros solidarios de una sola comunidad, la comunidad nacional".

${ }^{23}$ Traducción: “(...) esperaba sobrevivir generación tras generación toda la eternidad”.

24 Traducción: “(...) entre los que apoyan u organizan la desaparición de nuestra nación milenaria y los que están trabajando en su renovación, a los que se resignan a la borradura y los que luchan con pie firme por la grandeza de nuestro país".

Araucaria. Revista Iberoamericana de Filosofía, Política, Humanidades y Relaciones Internacionales, año $21, \mathrm{n}^{\circ} 42$. Segundo semestre de 2019. Pp. 605-628. ISSN 1575-6823 e-ISSN 2340-2199 doi: 10.12795/araucaria.2019.i42.26 
Permitidme que salude a unos cuantos soñadores. Esos jóvenes que llenaron las plazas de mayo, esos ciudadanos ejemplares que pararon desahucios con sus cuerpos jugándose la libertad. Esos héroes y heroínas de las batas blancas que defendieron el derecho a la salud y el trabajo digno para los profesionales sanitarios. Esos enfermos de hepatitis que tuvieron que ocupar hospitales para reivindicar su derecho a vivir. Esa marea verde que nos recordó que no hay democracia sin una educación pública de calidad. Esa clase obrera valiente, trabajadores de AENA, trabajadores de Coca-Cola: sois un ejemplo. Esos abuelos y abuelas incansables a los que llaman 'yayoflautas', que defendiendo su dignidad defienden la de sus hijos y la de sus nietos. Esos millares de jóvenes exiliados que nos están viendo por 'streaming': os prometo que construiremos un país para que podáis volver. Esas mujeres que tuvieron que recordar que nadie tiene el derecho a decidir sobre sus cuerpos. Esos estafados por las preferentes que señalaron cómo los ladrones más peligrosos usan gomina y corbata. Esos estudiantes que fueron la vanguardia de la comunidad universitaria. Esos trabajadores migrantes, nadie tiene derecho a llamaros extranjeros en España. Gracias. Gracias a todos por ser ese movimiento popular sin el cual el cambio no será posible en nuestro país.

Le Pen utiliza también la lógica de la equivalencia terminando sus discursos con un 'Vive la République Française!' o un 'Vive la France!', arengando todos los votantes con independencia de su voto: “(...) j’appelle tous les électeurs qui se sentent patriotes, quel que soit leur vote de premier tour" 25 . También apela a demandas de gran calado social en su país, por ejemplo, la defensa de la soberanía popular frente a otros centros de poder como la Unión Europea:

Si nous voulons le pouvoir, ce n'est pas pour nous, ce n'est pas pour en jouir comme ces notables installés du système, ce n'est pas pour le déléguer à d'autres instances comme les rois fainéants qui nous gouvernent, c'est pour le rendre au peuple qui est, dans notre démocratie et à nos yeux, le seul souverain dans notre pays ${ }^{26}$.

En ocasiones, las interpelaciones popular-democráticas asumen la forma de significantes vacíos (ambiguos) y flotantes (en disputa). Los significantes vacíos son categorías discursivas o unidades léxicas que tienen un significado (denotación) vago pero que connotativamente poseen o son susceptibles de poseer un sentido positivo para el pueblo, mientras que los flotantes son los que teniendo un significando difuso, su sentido connotativo está en disputa entre

\footnotetext{
25 Traducción: “(...) hago un llamamiento a todos los votantes que se sienten patriotas, con independencia de su voto en la primera ronda".

26 Traducción: "Si queremos el poder, no es para nosotros, no es para disfrutar como estos notables instalados en el sistema, no es para delegar en otras instancias como hacen los reyes vagos que nos gobiernan, es para hacer que el pueblo sea, en nuestra democracia y a nuestros ojos, el único soberano en nuestro país".
}

Araucaria. Revista Iberoamericana de Filosofia, Política, Humanidades y Relaciones Internacionales, año $21, \mathrm{n}^{\circ} 42$ Segundo semestre de 2019. Pp. 605-628. ISSN 1575-6823 e-ISSN 2340-2199 doi: 10.12795/araucaria.2019.i42.26 
las partes antagónicas ${ }^{27}$. El discurso populista "sutura" ${ }^{28}$ los vacíos y flotantes discursivos con significados que clarifican o disputan conceptos políticos aglutinadores procedentes de la tradición popular democrática, entre otros, democracia, patria, soberanía, república o progreso. La presencia y necesidad de este tipo de significantes en el discurso revela su carácter meramente formal y vacuo.

El discurso de Iglesias es muy esclarecedor en este punto. Podemos busca disputar al establishment dos conceptos flotantes: democracia y patria. El líder de Podemos define al primero de este modo:

Solo cuando los de abajo quieren y los de arriba no pueden se abre la posibilidad del cambio. Al cambio los de arriba lo llaman experimento y caos. Los de abajo lo llamamos democracia. ¿Qué es la democracia? La democracia es la posibilidad de cambiar lo que no funciona y lo que han hecho los gobiernos de este país no ha funcionado.

El concepto de patria (y de España), también es redefinido por Iglesias, pasando de ser una marca o una bandera que se cuelga en el balcón y se utiliza como pin o pulsera a convertirse en el símbolo de unidad de las distintas luchas y demandas sociales:

Nunca más España sin sus gentes, nunca más España como marca para que hagan negocios los ricos. No somos una marca, somos un país de ciudadanos, soñamos como don Quijote, pero nos tomamos muy en serio nuestros sueños. $\mathrm{Y}$ hoy decimos patria con orgullo y decimos que la patria no es un pin en la solapa, no es una pulsera. La patria es esa comunidad que asegura que se protege a todos los ciudadanos, que respeta la diversidad nacional, que asegura que todos los niños, sea cual sea el color de su piel, van limpios y calzados a una escuela pública, la patria es esa comunidad que asegura que a los enfermos se les atiende en los mejores hospitales con los mejores medicamentos. La patria es esa comunidad que nos permite soñar un país mejor, pero creyendo seriamente en nuestros sueños.

A diferencia de Iglesias, que disputa conceptos inclusivos de la tradición popular-democrática como democracia y patria, Le Pen prefiere resignificar la pertenencia a la nación en términos exclusivos, como asimilación de valores fundamentales frente la 'tarte à la crème'29 de los partidarios de la multiculturalidad: "Mais la République française impose aussi de se plier à

\footnotetext{
${ }^{27}$ Como señala Laclau (2007), los significantes vacíos (retórica) se encuentran al lado del pueblo mientras que los significantes flotantes (dialéctica) están a un lado y al otro de la frontera que separa al pueblo de su antagonista.

${ }^{28}$ Laclau toma este concepto y los de significantes vacíos y flotantes de la teoría psicoanalítica de Lacan.

${ }^{29}$ Esta expresión francesa se asimila a la española "lugar común".
} 
la règle commune, à nos coutumes et à nos modes de vie, au respect de nos principes de vie, à l'acceptation de nos valeurs fondatrices" ${ }^{\prime 30}$.

Como se observa en estos ejemplos, el discurso populista es político. Este tipo de discursos, a diferencia del científico, tienen como objetivo "impulsar a la acción, son menos útiles las argumentaciones cuidadosamente trabajadas que los efectos estéticos, las imágenes impresionantes y las apelaciones emotivas" (Álvarez-Junco 1990: 234). De ahí que el elemento lingüístico clave sea la disociación entre el verdadero significado (denotación) de las palabras y las imágenes que evocan (connotación). Este proceso se lleva a cabo no solo mediante los significantes vacíos y flotantes sino también a través de figuras retóricas como la metáfora, la metonimia y sobre todo la sinécdoque, que sirven para representar las diferencias particulares en forma total e inconmensurable ${ }^{31}$ (Laclau 2007).

El discurso de Iglesias contiene varias sinécdoques que tratan de representar el todo mediante una parte. Por ejemplo, en la frase "Fue el pueblo de Madrid, ese que hoy está en la calle con nosotros, el que compró con sacrificio la dignidad frente a una invasión intolerable", los madrileños que resistieron a la invasión francesa de comienzos del siglo XIX representan al actual pueblo español que se opone a las políticas de austeridad dictadas por Alemania. Y en la oración "No permitamos que los traidores conviertan al Quijote en una marca", el Quijote simboliza al país, a la patria soberana. El uso de la sinécdoque en Le Pen es igualmente efectivo; la lideresa francesa trata de representar la ruptura del sistema de partidos tradicional en Francia como el agrietamiento de un muro antes infranqueable:

Comme en 1989 avec l'effondrement du monde soviétique, nous avons entendu les craquements d'un mur qui se fissure, d'un mur derrière lequel un système archaïque se croyait protégé du monde et du temps, un mur derrière lequel une Caste dirigeante espérait se survivre de génération en génération durant l'éternité32.

Otros recursos lingüísticos del discurso populista que buscan generar emoción en el auditorio son el uso de frases grandilocuentes, la repetición (muy

\footnotetext{
${ }^{30}$ Traducción: "Pero la República francesa exige también someterse a la regla común, a nuestras costumbres y nuestra forma de vida, para que respeten nuestros principios de vida, a la aceptación de nuestros valores fundamentales".

${ }^{31}$ La totalidad es tan solo una simple apariencia porque lo universal es algo a la vez imposible y necesario. Como apunta Laclau (2007: 149), "el único horizonte totalizador posible está dado por una parcialidad (la fuerza hegemónica) que asume la representación de una totalidad mítica". Sobre la utilización política de las metáforas, metonimias y otras figuras retóricas, véase Aristóteles (2014).

${ }^{32}$ Traducción: "Al igual que en 1989 con el colapso del mundo soviético, oímos los crujidos de un muro que se agrieta, de un muro detrás del cual un sistema arcaico se cree protegido del mundo y del tiempo, un muro detrás del cual una Casta gobernante esperaba sobrevivir generación tras generación a través de la eternidad".
} 
utilizada tanto en el discurso de Iglesias: "nos tomamos muy en serio nuestros sueños", como en el de Le Pen con la metáfora del muro) y las alusiones a un pasado heroico. Este último trata de entroncar las luchas actuales con los grandes acontecimientos del pasado colectivo con el fin de construir hegemonía ${ }^{33}$. En palabras de Lenin, "el populismo se asemeja a Jano que mira con un rostro hacia el pasado y con otro hacia el futuro" (cit. en Torres 1987: 157). Ejemplos de este tipo de recursos son la referencia de Iglesias a los acontecimientos del 2 de mayo de 1808 en Madrid o el llamamiento que hace Le Pen de restaurar las capacidades y costumbres de Francia cuando define a su partido como "une alternance durable car fondée sur des valeurs millénaires qui ont fait la France: le courage, le dévouement, le travail, la recherche du progrès" 34 .

Pudiera pensarse que todas estas características formales podrían estar presentes en cualquier discurso político, pero lo que caracteriza al discurso populista es la presencia simultánea de todas ellas. En un contexto de hegemonía neoliberal en el que lo político se entiende más como una cuestión racional, técnica o administrativa, el populismo discursivo es una excepcionalidad ya que apela a las pasiones y trata de construir identidades políticas (Errejón y Mouffe 2015).

\section{Contenido vacuo y disputado: populismo democrático y populismo excluyente}

Aunque algunos teóricos liberales encuentran similitudes en el contenido de los discursos populistas (Germani 1978; De la Torre 1987; Freidenberg 2007; Panizza 2008), no es difícil percatarse de lo diferentes que han sido los diversos movimientos populistas desde mediados del siglo XIX hasta hoy. Los discursos de Benito Mussolini, Juan Domingo Perón, Margaret Thatcher o Hugo Chávez, por poner algunos ejemplos, no solo no se parecían sino que eran ideológicamente antagónicos. En este sentido, teóricos como Canovan (2004) no iban muy desencaminados cuando renunciaron a definir este fenómeno por su vacuidad y optaron por distinguir tipologías.

En un primer momento, los posmarxistas describieron al populismo como un fenómeno ideológico y distinguieron dos tipos de populismo: de las clases dominantes, y socialista o de las clases dominadas. Sobre este último Laclau (1978: 203) sostuvo:

Un populismo socialista no es la forma más atrasada de ideología obrera, sino su forma más avanzada: el momento en que la clase obrera ha logrado condensar

33 Así, el populismo posee un rasgo revolucionario, si se entiende revolución en el sentido etimológico señalado por Arendt (1988), como restauración de lo pasado con la mirada puesta en el futuro.

34 Traducción: “(...) una alternativa viable porque se basa en los valores milenarios que han construido a Francia: el coraje, la dedicación, el trabajo y la búsqueda del progreso”. 
en su ideología el conjunto de la ideología democrática en una formación social determinada. De ahí el carácter inequívocamente "populista" que adoptan los movimientos socialistas victoriosos.

Pero más adelante, se concibió como una estrategia que adopta un contenido $\mathrm{u}$ otro en función del significado que el emisor otorgue a los significantes vacíos y flotantes en su discurso público; como una forma de construir lo político no asociada a ninguna ideología específica (Laclau 2007; Errejón y Mouffe 2015).

Combinando ambos criterios, aquí se distinguen dos tipos de discursos populistas, no según su adscripción de clase (como hizo Laclau) sino en función de su visión de la democracia y la naturaleza de sus demandas: el populismo democrático, que busca ampliar los espacios de participación de los sectores excluidos de la política, cuyo ejemplo es Podemos en España; y el populismo excluyente, que persigue la reafirmación de un demos oponiéndolo a 'otro' al que pretende mantener fuera de la comunidad política, como el Frente Nacional en Francia. En términos de Mouffe (2011), el populismo democrático se enmarcaría dentro de la política agonista, que tiene lugar entre adversarios que respetan las reglas de la democracia pluralista, mientras que el excluyente estaría dentro del ámbito de la política antagonista que responde a la distinción schmittiana de amigo-enemigo ${ }^{35}$.

El primer tipo de populismo apela al pueblo y lo confronta con el antipueblo, pero no excluye a este último del proceso democrático. Si bien este discurso genera polarización política al simplificar el campo político en dos bloques antagónicos, no pretende imponerse al otro por la fuerza sino disputarle el dominio hegemónico mediante los mecanismos propios de la democracia (elecciones, referéndums, consultas populares, etc.). Como se puede observar en el discurso de Iglesias, este tipo de populismo "sueña con un país donde nadie se quede fuera" y no con un régimen que priorice a unos ciudadanos sobre otros.

De igual modo, en el populismo democrático el antipueblo, también llamado élite o casta, no es malo per se sino por sus acciones, porque se preocupa solamente de sí mismo y no toma en consideración al pueblo. El discurso del líder de Podemos es revelador al respecto:

${ }^{35}$ En la política agonista el antipueblo no es el enemigo sino el adversario, "que es un 'enemigo legítimo' que se va a tratar de vencer pero de una manera que respeta las instituciones democráticas" (Errejón y Mouffe 2015: 120). La propuesta de Mouffe es un intento de superar las dificultades que tiene combinar en una misma propuesta teórica (la democracia agonista), ideas que son en principio contradictorias: la radicalización de la democracia liberal que propone la autora y la lógica profundamente antiliberal de lo político que defiende Carl Schmitt. Mouffe acepta parcialmente la crítica del jurista alemán sobre la imposibilidad de una política liberal basada en el consenso en torno a valores universales, pero rechaza su propuesta de antagonismo no-democrático y, en lugar de ella, plantea que la posibilidad de combinar las instituciones representativas liberales con una lógica de lo político sustentada en el conflicto entre posiciones políticas adversarias.

Araucaria. Revista Iberoamericana de Filosofia, Política, Humanidades y Relaciones Internacionales, año $21, \mathrm{n}^{\circ} 42$. Segundo semestre de 2019. Pp. 605-628. ISSN 1575-6823 e-ISSN 2340-2199 doi: 10.12795/araucaria.2019.i42.26 


\begin{abstract}
¿Qué ha pasado? ¿Qué ha pasado en este país? Esta situación de humillación y empobrecimiento no se explica solo porque haya gobernado mala gente, no se explica porque sean negligentes, el problema es un modelo de país que ha puesto a trabajar al Estado contra la sociedad, una minoría que engordaba sus cuentas mientras que la mayoría veía cómo las suyas adelgazaban, eso es la corrupción; robar las instituciones a la gente.
\end{abstract}

Este tipo de populismo actúa como un modo de hacer política en interés de aquellos que están excluidos o desencantados con la política y, para ello, se recupera el tono propio de lo político: la lógica amigo-enemigo/adversario ${ }^{36}$ (Laclau 2008; Mouffe 2011; Schmitt 2014). Por eso, se articulan demandas que no buscan restringir las libertades democráticas o excluir a un grupo del demos político, sino ampliar el horizonte de los derechos constitucionales. En su discurso, Iglesias habla de garantizar las pensiones de los mayores, potenciar las pequeñas y medianas empresas, invertir en investigación y desarrollo $(\mathrm{I}+\mathrm{D}+\mathrm{i})$, lograr la soberanía tecnológica, energética y alimentaria, o cambiar el modelo productivo para caminar hacia una economía verde.

Frente al populismo democrático, el excluyente tiene como objetivo reivindicar a un demos contraponiéndolo con un "otro" (inmigrante, extranjero, terrorista, etc.) al que se quiere mantener fuera de la comunidad política (Laclau 2007). Un ejemplo de este tipo de populismo es el étnico. Aunque Laclau lo excluye de su teoría porque considera que la vacuidad de sus significantes está muy limitada, su discurso presenta una estructura formal populista, como se ha comprobado en el apartado anterior con el caso de Le Pen ${ }^{37}$.

En cuanto su contenido, el discurso de la lideresa del Frente Nacional articula demandas sociales de tipo económico, como la lucha contra el desempleo, con otros temas relacionados con la seguridad, el terrorismo y la inmigración. Generalmente Le Pen reproduce este tipo de contenidos de forma sutil: defendiendo la asimilación de los valores republicanos y de "la survie des Français en tant que peuple" ${ }^{38}$, criticando a los defensores de la multiculturalidad, o acusando a rivales políticos como Christian Estrosi de organizar "la submersion migratoire du pays avec les migrants" 39 .

No obstante, el contenido excluyente y étnico de este tipo de populismo a veces se expone con mayor claridad, por ejemplo después de situaciones dramáticas como los atentados de París del 13 de noviembre. En una intervención realizada horas después del suceso, Le Pen (14 de noviembre de 2015) relacionó

${ }^{36}$ El populismo actúa así "como una posibilidad distintiva y siempre presente de estructuración de la vida política” (Laclau 2007: 27-28).

37 Este tipo de discurso no es exclusivo de los partidos fascistas y de extrema derecha sino que están presentes en formaciones y movimientos políticos ubicados en cualquier posición del espectro ideológico. Ejemplos de este tipo de populismo son Milosevic en la antigua Yugoslavia o Donald Trump en Estados Unidos.

38 Traducción: “(...) de la supervivencia del Francés como pueblo”.

39 Traducción: “(...) la inundación migratoria del país con los migrantes”. 
la inseguridad y los atentados islamistas con la presencia de extranjeros en el país y propuso, entre otras medidas, aniquilar el fundamentalismo islámico, prohibir las organizaciones islamistas, cerrar las mezquitas radicales y deportar a los extranjeros "qui prêchent la haine sur notre sol, ainsi que les clandestins qui n'ont rien à y faire"

Si bien los discursos de Iglesias y Le Pen se asimilan en la estructura formal (apelación al pueblo, creación de identidad popular, lógicas de la diferencia y la equivalencia, uso de significantes vacíos y flotantes o utilización de figuras retóricas como la sinécdoque), es decir, utilizan una estrategia política populista, son antagónicos en su contenido ya el primero asume demandas democráticas y el segundo aboga por restringir derechos y libertades.

De esta manera, en función de su contenido, la estrategia populista puede ser un riesgo para la democracia (populismo excluyente) o una herramienta oportuna para el cambio político (populismo democrático). Es más, para Errejón y Mouffe (2015) la mejor forma de enfrentar al populismo excluyente es lograr que las fuerzas democráticas disputen a la extrema derecha el terreno de la construcción de identidades populares. Como afirma Errejón:

Es un error regalarle a las fuerzas más reaccionarias la posibilidad de representar ellos una idea de país, un proyecto de patria fuerte construida contra los más débiles, contra los que vienen de afuera, contra las naciones minoritarias o en forma chauvinista en vez de reconstruir una idea cívica, popular y democrática de país, con instituciones sólidas y garantistas, solidario e incluyente. Un patriotismo democrático, progresista y popular (Errejón y Mouffe 2015: 60).

\section{Reflexiones finales}

El populismo puede definirse de diversas formas: como un fenómeno de masas, como un movimiento político fruto de una coyuntura histórica concreta, como un concepto inabarcable que no se puede definir sino tan solo intuir, o como una estrategia discursiva que busca ejercer el poder para lograr el cambio político. Este artículo entiende el populismo de esta última manera. Respecto a la relación del populismo con la democracia existen dos visiones: la liberal, que lo percibe como un riesgo para las instituciones representativas, y la posmarxista, que lo concibe como una oportunidad de cambio y de ampliación del espacio público.

Como estrategia política, el populismo se caracteriza por la estructura formal de su discurso y no por su contenido. El discurso populista se basa en la apelación al sujeto pueblo y en la creación de identidad popular a través de

\footnotetext{
${ }^{40}$ Traducción: “(...) que fomenten el odio en nuestro suelo, así como a los inmigrantes ilegales que no tienen nada que hacer".
}

Araucaria. Revista Iberoamericana de Filosofia, Política, Humanidades y Relaciones Internacionales, año $21, \mathrm{n}^{\circ} 42$. Segundo semestre de 2019. Pp. 605-628. ISSN 1575-6823 e-ISSN 2340-2199 doi: 10.12795/araucaria.2019.i42.26 
las lógicas de la diferencia y la equivalencia y de diversos recursos retóricos vinculados a esta última; ambos elementos son visibles en los discursos de Iglesias y Le Pen.

Las conclusiones del presente artículo son, en primer lugar, que el populismo como estructura discursiva formal, no supone en sí mismo un riesgo para la democracia. Constituye una amenaza a los valores democráticos cuando su contenido sustancial es excluyente y antidemocrático, como ocurriría con cualquier otra estructura discursiva formal que recogiera este tipo de contenido. Un ejemplo de ello es la intervención de Le Pen y sus demandas regresivas hacia los derechos y las libertades de las personas.

En segundo lugar, se advierte que el discurso formalmente populista cuyo contenido prioriza en las demandas inclusivas y democráticas, como el de Iglesias, puede ayudar a ampliar los espacios de participación pública. De este modo, el populismo como estrategia discursiva puede ser una herramienta para impulsar el cambio político, no solo hacia regímenes autoritarios, corporativistas o neoliberales sino también hacia modelos de Estado más sociales, participativos e incluyentes como los que defienden algunos movimientos políticos y gobiernos de izquierda en América Latina y Europa.

Como observación final, la estrategia discursiva populista resulta útil para el logro y ejercicio del poder político en democracias pluralistas, siempre que articule demandas democráticas y no excluyentes hacia fuera (Laclau y Mouffe 1987), porque reivindica dos de los aspectos centrales de la tradición democrática: apela a la mayoría y defiende la soberanía popular ${ }^{41}$.

Pero también implica un riesgo grave: que a través de ella se articulen discursos contrarios a las tradiciones democráticas que pongan en peligro los derechos y libertades conquistados por las propias masas. Desacreditar a los votantes o negar la naturaleza conflictiva de lo político forzando alianzas políticas contra natura como si no existieran intereses contrapuestos, no solo no evita el populismo excluyente sino que lo alimenta. Esta estrategia consensual y defensiva no ha impedido que la extrema derecha haya entrado a 17 parlamentos nacionales de la Unión Europea, y forme parte del gobierno en países tan relevantes como Hungría, Polonia, Eslovenia, Estados Unidos, Austria, Italia o, más recientemente, Brasil. Frente a esto último, la solución que aquí se propone es tomar el control del juego político y disputar el campo hegemónico, articulando demandas incluyentes y democráticas; para ello, urge superar los prejuicios liberales y adoptar una estrategia política con mayor arrojo, basada en el populismo democrático.

${ }^{41}$ En este sentido, el populismo es connatural a la democracia en cuanto esta última es la forma de gobierno del pueblo. No es incompatible con la estrategia populista que la democracia haya asumido postulados de la tradición liberal como la garantía de los derechos individuales y la separación de poderes.

Araucaria. Revista Iberoamericana de Filosofía, Política, Humanidades y Relaciones Internacionales, año $21, \mathrm{n}^{\circ} 42$. Segundo semestre de 2019. Pp. 605-628. ISSN 1575-6823 e-ISSN 2340-2199 doi: 10.12795/araucaria.2019.i42.26 


\section{Referencias bibliográficas:}

Althusser 2014: L. Althusser, "Ideología y Aparatos Ideológicos de Estado" [en

S. Žižek, comp., Ideología. Un mapa de la cuestión, Buenos Aires, Fondo de Cultura Económica, 2014], pp. 115-155.

Álvarez-Junco 1987: J. Álvarez-Junco, comp., Populismo, caudillaje y discurso demagógico (Madrid: Centro de Investigaciones Sociológicas, 1987).

Álvarez-Junco 1990: J. Álvarez-Junco, El emperador del paralelo. Lerroux y la demagogia populista (Madrid, Alianza, 1990).

Arendt 1987: H. Arendt, Los orígenes del totalitarismo (Madrid, Alianza, 1987).

Arendt 1988: H. Arendt, Sobre la revolución (Madrid, Alianza, 1988).

Aristóteles 2000: Aristóteles, La política (Bogotá, Panamericana, 2000).

Aristóteles 2000: Aristóteles, Retórica (Madrid, Alianza, 2014).

Canetti 2013: E. Canetti, Masa y poder (Madrid, Alianza, 2013).

Canovan 1981: M. Canovan, Populism (Londres, Juction Books, 1981).

Canovan 2004: M. Canovan, "Populism for Political Theorists?" en Journal of Political Ideologies, 9 (3) (2004), pp. 241-52.

Cardoso y Faletto 1969: F. H. Cardoso y E. Faletto, Dependencia y desarrollo en América Latina. Ensayo de interpretación sociológica (México, Siglo XXI, 1969).

Carlin 15 de febrero de 2016: J. Carlin, "Trump: El Pato Donald para presidente" [en El País, 15 de febrero de 2016, disponible en: https://goo. $\mathrm{gl} / \mathrm{PRKmPT}]$.

De la Torre 2000: C. De la Torre, Populist Seduction in Latin America. The Ecuatorian Experience (Athens, Ohio University Press, 2000).

De la Torre 2015: C. De la Torre, De Velasco a Correa. Insurrecciones, populismo y elecciones en Ecuador, 1944-2013 (Quito, Universidad Andina Simón Bolívar - Corporación Editora Nacional, 2015).

Di Tella 2015: T. Di Tella, "Populismo y reforma en América Latina" en Desarrollo Económico, IV (16) (2015), pp. 391-425.

DRAE 2014: DRAE, Diccionario de la Real Academia Española. $23^{a}$ Edición (Madrid, Espasa, 2014).

Errejón y Mouffe 2015: Í. Errejón y C. Mouffe, Construir pueblo. Hegemonía y radicalización de la democracia (Barcelona, Icaria, 2015).

Freidenberg 2007: F. Freidenberg, La tentación populista (Madrid, Síntesis, 2007).

García-Abadillo 17 de mayo de 2015: C. García-Abadillo, “Pablo Iglesias: 'El populismo de izquierdas es clave para el cambio"” [en El Mundo, 17 de mayo de 2015, disponible en: https://goo.gl/etoc2i]. 
Germani 1962: G. Germani, Política y sociedad en una época de transición (Buenos Aires, Paidós, 1962).

Germani 1978: G. Germani, Authoritarism, Fascism and National Populism (New Brunswick, Transaction, 1978).

Gramsci 1981: A. Gramsci, Cuadernos de la cárcel (México, Era, 1981).

Ianni 1973: O. Ianni, La formación del Estado populista en América Latina (México, Era, 1973).

Iglesias 31 de enero de 2015: P. Iglesias, "Soñadores de la patria" [en Beers and Politics, 31 de enero de 2015, disponible en: https://goo.gl/hUPqf1].

Ionescu 1969: G. Ionescu, "Eastern Europe" [en G. Ionescu y E. Gellner, comps., Populism: Its Meaning and National Charasteristics, Londres, Weidenfeld and Nicolson, 1969], pp. 97-121.

Ionescu y Gellner 1969: G. Ionescu y E. Gellner, comps., Populismo. Sus significados y características nacionales (Buenos Aires, Amorrortu, 1969).

Knight 1998: A. Knight, "Populism and Neo-populism in Latin America, especially Mexico", en Journal of Latin American Studies, 30 (2) (1998), pp. 223-48.

Krauze 14 de octubre de 2005: E. Krauze, "Decálogo del populismo iberoamericano" [en El País, 14 de octubre de 2005, disponible en: http:// xurl.es/gfq31].

Laclau 1978: E. Laclau, Política e ideología en la teoría marxista. Capitalismo, fascismo, populismo (Madrid, Siglo XXI, 1978).

Laclau 1993: E. Laclau, Nuevas reflexiones sobre la revolución de nuestro tiempo (Buenos Aires, Nueva Visión, 1993).

Laclau 2007: E. Laclau, La razón populista (Buenos Aires, Fondo de Cultura Económica, 2007)

Laclau 2008: E. Laclau, Debates y combates. Por un nuevo horizonte de la política (Buenos Aires, Fondo de Cultura Económica, 2008).

Laclau y Mouffe 1987: E. Laclau y C. Mouffe, Hegemonía y estrategia socialista. Hacia una radicalización de la democracia (Madrid, Siglo XXI, 1987).

Lassalle 2017: J. M. Lassalle, Contra el populismo: cartografía de un totalitarismo posmoderno (Barcelona, Debate, 2017).

Lambert 1964: J. Lambert, América Latina. Estructuras sociales e instituciones politicas (Barcelona, Ariel, 1964).

Lasch 1996: C. Lasch, La rebelión de las élites y la traición a la democracia (Barcelona, Paidós, 1996).

Le Bon 1968: G. Le Bon, Psicología de las multitudes (Buenos Aires, Albatros, 1968). 
Le Pen 10 de diciembre de 2015: M. Le Pen, "Discours de Marine Le Pen à Paris" [en Front National, 10 de diciembre de 2015, disponible en : https:// goo.gl/bxvfqu].

Le Pen 14 de noviembre de 2015 : M. Le Pen, "Déclaration de Marine Le Pen" [en Front National, 14 de noviembre de 2015, disponible en: https://goo. $\mathrm{gl} / 1$ ofcWo].

Lenin 1978 : V. I. Lenin, La lucha de los pueblos de las colonias y países dependientes contra el imperialismo (Moscú, Progreso, 1978).

Lenin, 1979: V. I. Lenin, Quienes son los 'amigos del pueblo'y cómo luchan contra los socialdemócratas (Moscú, Progreso, 1979).

Mair 2002: P. Mair, "Populist Democracy vs Party Democracy" [en Y. Mény e Y. Surel, eds., Democracies and the Populist Challenge, Basingstoke, Palgrave, 2002], pp. 81-98.

Macpherson 1997: C. B. Macpherson, La democracia liberal y su época (Madrid, Alianza, 1997).

Moscoso 1989: C. Moscoso, El populismo como ideología en América Latina (Madrid, Universidad Complutense de Madrid, 1989).

Mouffe 2011: C. Mouffe, En torno a lo político (Buenos Aires, Fondo de Cultura Económica, 2011).

Mude y Rovira 2013: C. Mude y C. Rovira, "Populism and (liberal) democracy: a framework for analysis" [en C. Mudde y C. Rovira, eds., Populism in Europe and the Americas, Cambridge, Cambridge University Press, 2013], pp. 1-26.

Ochoa y Prado 2017: L. Ochoa y J. P. Prado, “Cosmopolitismo, constructivismo y liberalismo institucional: diálogo teórico en torno a la cooperación internacional para el desarrollo", en Araucaria, en Revista Iberoamericana de Filosofí, Política y Humanidades, (37) (2017), pp. 273-299.

Ortega y Gasset 2009: J. Ortega y Gasset, La rebelión de las masas (Madrid, Revista de Occidente, 2009).

Panizza 2008: F. Panizza, "Fisuras entre populismo y democracia en América Latina”, en Stockholm Review of Latin American Studies, 3 (2008), pp. 81-93.

Quiroga 2013: M. V. Quiroga, "Perspectivas para el análisis de la acción colectiva: algunas reflexiones críticas y posibles aportes desde la teoría de la hegemonía", en Araucaria. Revista Iberoamericana de Filosofía, Politica y Humanidades, (30) (2013), pp. 25-44.

Rivas 2018: J. M. Rivas, "De la clase al pueblo: una revisión crítica de la teoría marxista de la lucha de clases" [en A. Tarín y J. M. Rivas, coords., La clase trabajadora. ¿Sujeto de cambio en el siglo XXI?, Madrid, Siglo XXI España, 2018], pp. 29-52. 
Roberts 1999: K. Roberts, "El neoliberalismo y la transformación del populismo en América Latina. El caso peruano" [en M. M. Mackinnon y M. A. Petrone, comps., Populismo y neopopulismo en América Latina. El problema de la Cenicienta, Buenos Aires, Eudeba, 1999].

Romero 1996: A. Romero, Miseria del populismo: mitos y realidades de la democracia en Venezuela (Caracas, Panapo, 1996).

Rudé 1964: G. Rudé, The Crowd in History. A Study of Popular Disturbances in France and England (1730-1848) (Nueva York, John Wiley and Sons Inc., 1964).

Schmitt 2014: C. Schmitt, El concepto de lo político (Madrid, Alianza, 2014).

Torres 1987: S. Torres, "El populismo. Un concepto escurridizo" [en J. ÁlvarezJunco, comp., Populismo, caudillaje y discurso demagógico, Madrid, Centro de Investigaciones Sociológicas, 1987], pp. 159-180.

Walicki 1971: A. Walicki, Populismo y marxismo en Rusia (Barcelona, Estela, 1971).

Weber 2006: M. Weber, "El político y el científico" [en vV.AA., El político como un líder democrático. Desafíos y oportunidades de nuevos liderazgos democráticos, Buenos Aires, Instituto Lebensohn, 2006], pp. 9-59.

Weyland 2004: K. Weyland, "Clasificando un concepto: el populismo en los estudios sobre América Latina” [en vv.AA., Releer los populismos, Quito, Corporación Andina de Acción Popular, 2004], pp. 9-50.

Worsley 1966: P. Worsley, Tercer Mundo, una fuerza vital en los asuntos internacionales (México, Siglo XXI, 1966). 